\title{
ANA GARDUÑO
}

\section{Pago en Especie: a 55 años de un convenio patrimonializador}

$\mathrm{E}$ N I947, MEDIANTE UNA REFORMA tributaria, la mayoría de los artistas plásticos que producían en México fueron incorporados al sistema hacendario, dentro del rubro de profesionistas que pagan los impuestos correspondientes — en moneda nacional — por la enajenación directa de su trabajo. ${ }^{I}$ No obstante, a una elite de creadores ubicados en diversas esferas de las artes (teatrales, musicales, literarias, etcétera) se le concedió la exención fiscal por derechos patrimoniales; de esta forma, una minoría selecta del movimiento plástico que surgió a partir de I92 I no pagó impuestos por la comercialización de sus obras hasta su muerte: Diego Rivera, David Alfaro Siqueiros, Gerardo Murillo (Dr. Atl) y Rufino Tamayo, entre otros. ${ }^{2}$

Diez años después de que se implementara esta política fiscal, un grupo de pintores, promotores culturales y funcionarios hacendarios ideó un programa vanguardista para que la mayoría de los creadores plásticos activos tuviera la opción de cubrir las alcabalas también en especie; de esta forma, desde hace 55 años el propio creador selecciona las obras de arte a entregar a la Secretaría de

I. La reforma tributaria de 1947 se refrendó con la Ley del Impuesto Sobre la Renta de diciembre de 1953, que gravaba los ingresos provenientes del capital (del trabajo o de la combinación de ambos) de profesionistas, técnicos, artesanos y artistas.

2. Aunque hay indicios de que la exención fiscal por derechos patrimoniales se autorizó desde I947, el escritor Gabriel Zaid la ubica siete años después: "Un ilustre secretario de Hacienda Antonio Carrillo Flores [...] volvió explícita la exención autoral en la Ley del Impuesto sobre la Renta. La exención estuvo vigente de I954 a I990", en "Razones para la exención", Vuelta, núm. I96, marzo de i993, p. 44. 
Hacienda y Crédito Público (SHCP). Lo grave es el mecanismo elegido para la valoración de los objetos: hasta 1994 cada artista le adjudicaba un precio a las piezas que enviaba y después se optó por una cuantificación básica mediante una tabla numérica: por cada cinco trabajos vendidos al año se entrega una, ¿y la calidad? Peor aún, prácticamente no es posible rechazar lo que se entrega.

Cuando en 1957 se publicitó la inminencia del Programa Pago en Especie destinado en exclusiva a los creadores plásticos, en ese tiempo únicos usufructuarios de la categoría de héroes culturales del régimen, fueron justamente los pintores colocados en la cúspide de la pirámide artística los que apoyaron, en los hechos o en los discursos, el nuevo dispositivo hacendario. Si bien quienes apadrinaron el proyecto continuaron gozando de una exención de impuestos que hasta finales de los años cuarenta había sido generalizada, varios de ellos incluso cedieron alguna obra, como ocurrió con Rufino Tamayo y el siempre generoso Diego Rivera.

David Alfaro Siqueiros encabezó la campaña de propaganda y posó para las fotografías oficiales junto con Hugo B. Margáin Gleason (político adscrito al grupo de poder de Antonio Carrillo Flores; entre 1952 y 1959, director general del Impuesto sobre la Renta). No obstante el publicitado compromiso de Siqueiros con el proyecto, por no estar obligado a entregar obra, no lo hizo. En la exégesis oficial del origen de dicho dispositivo, hoy ya mítico, se cita tradicionalmente a sus publicistas como autores intelectuales:

Un día de 1957, David Alfaro Siqueiros llegó a las oficinas de Hugo B. Margáin [...] El pintor tenía organizado a un grupo de artistas, muchos de ellos con amenaza de embargo y otros ya embargados, en todos los casos, por no haber pagado sus impuestos a tiempo. Con vehemencia, el artista alegó que un pintor no sabía de contabilidad ni de leyes impositivas. "Lo único que tenemos son cuadros, y si quieres, podemos pagar nuestras obligaciones con alguna obra", afirmó Siqueiros. ${ }^{3}$

Poco se menciona el activo papel desempeñado por los asesores: el abogado Arturo Carrillo Gil (hermano del empresario farmacéutico y coleccionista Álvar Carrillo Gil), la segunda directora del Salón de la Plástica Mexicana (SPM), Carmen Marín de Barreda, y la dueña de la Galería de Arte Mexicano, Inés

3. Esta popular versión circula en innumerables catálogos del Museo de la Secretaría de Hacienda-Palacio del Antiguo Arzobispado, en notas de prensa e internet. Véase el resumen publicado en la página impuestum.com, Reforma, 3 de junio de 2003 (http://www.impuestum. $\mathrm{com} /$ noticias/ I 877 .html? PHPSESSID = If 5 f 4055 f I I 074 fcaa I a $47 \mathrm{df} 9 \mathrm{f} 853 \mathrm{I} \mathrm{ed}$ ). 
Amor, comprometida promotora que, entre sus múltiples funciones, se desempeñó como valuadora de las obras de arte producidas por la modernidad. ${ }^{4}$

De inmediato se adhirieron a esta opción tributaria artistas como Lola Cueto, Angelina Beloff, Mariana Yampolsky, Raúl Anguiano, Amador Lugo, Luis Nishizawa, Fernando Castro Pacheco, Adolfo Best Maugard, Agustín Lazo, Ignacio Asúnsolo, Gustavo Montoya y Guillermo Meza, con lo que se evidencia que el Programa Pago en Especie se fraguó como una herramienta destinada a favorecer prioritariamente a miembros de la entonces conocida como Escuela Mexicana de Pintura. Los artistas que apostaban a corrientes vanguardistas, más cercanas a los lenguajes plásticos imperantes en Europa y los Estados Unidos, agrupados bajo lo que se ha denominado ruptura, no fueron convocados en 1957 , a pesar de que ya disponían de una significativa producción y ciertamente tenían mercado, aunque incipiente: en 1952 se había fundado la Galería Prisse; en 1954, la Proteo y la Havre, y dos años después la de Antonio Souza.

Jorge Juan Crespo de la Serna, un crítico de arte, apela al imaginario colectivo, que estandariza la personalidad del creador plástico dentro de los cánones del posromanticismo y la bohemia para legitimar su incapacidad de tasar el monto de sus contribuciones:

Los artistas plásticos [...] no son lo que se conoce vulgarmente como "gente práctica", es decir, que tenga los pies en la tierra y sepa desenvolverse en este punto como todo el mundo. Unos son unos bohemios, otros unos olvidadizos, los demás unos indiferentes [...] Andan por las nubes, de donde tal vez sacan su mejor inspiración [...] ¿Cómo exigirles que rindan cuentas de lo que ganan con sus productos artísticos? [...] Hay lagunas en sus cálculos, desorden. ${ }^{5}$

Al mismo tiempo, subraya que el Programa Pago en Especie consolida la intervención estatal y socava el coleccionismo privado, dado que es un dispositivo "antiapetito individual" que persigue un objetivo "de tipo socialista" en la medida en que garantiza la transferencia de una parte de las ganancias a la sociedad, dado que la propiedad estatal de aquellas obras de arte las transforma automáticamente en patrimonio nacional.

4. Véase Hugo B. Margáin, testimonio sin título con fecha del 3 de septiembre de 1982, Colección Pago en Especie de la SHCP 1975-1984, México, Secretaría de Hacienda y Crédito Público, I984, s.p.; Jorge Juan Crespo de la Serna, "Novedad: los pintores pagan con cuadros sus impuestos", México en la Cultura, suplemento de Novedades, núm. 45 I, I I de noviembre de 1957, p. 6.

5. Crespo de la Serna, op. cit. 
No obstante, desde años anteriores se había ventilado cierta oposición hacia ese tipo de gravámenes. En 1950, como respuesta a la reforma tributaria de I947, el coleccionista de arte moderno Álvar Carrillo Gil publicó un artículo en el que se ocupó de la política fiscal y mercadotécnica en relación con la producción plástica; con la radicalidad que lo caracterizaba, se pronunció en contra de la aplicación de dos gabelas a los pintores por la comercialización de sus piezas - una cuando celebraban una transacción de compraventa en el ámbito local y otra en caso de que la pieza se exportara de manera definitiva. ${ }^{6}$ Confirma la sistematicidad de un habitus cultural: los artistas acostumbraban evadir el impuesto por mercadeo interno en negociaciones con consumidores nacionales, extendiendo sólo las imprescindibles facturas requeridas para extraditar legalmente las piezas vendidas; esto explica por qué en los archivos de los coleccionistas privados locales, concentrados en acumular arte moderno mexicano, casi no se conservan recibos y mucho menos facturas. Más aún, Carrillo Gil manifestó su desconcierto ante la pasividad de los artistas locales, quienes no organizaron protestas ni manifestaron públicamente su oposición a una reforma tributaria que los afectaba.

Como un ejemplo a seguir, el coleccionista recordó el caso de El Greco (I54II6I4), quien ganó un juicio contra las autoridades que le exigían el pago de impuestos, logrando que se eliminaran tales contribuciones no sólo a él sino a todos los pintores contemporáneos que producían en España. No obstante el tono provocador de este artículo de tan polémico promotor cultural, parece que no generó una amplia repercusión, sino que más bien formó parte de una serie de discusiones, hoy ya olvidadas, sobre si debía continuar o cancelarse la exoneración del pago de gravámenes a los pintores.

La desaparición física del último de los llamados cuatro grandes, Rufino Tamayo (I99I), prácticamente coincidió con la disolución del tipo de relación, clientelar y muy cercana, entre los pintores y el Estado. La exención tributaria se mantuvo hasta 1990, cuando se sometió a severas restricciones para un ańo después abolirla, no sin múltiples reclamos por parte de una elite en la que ya predominaban los literatos; ante la presión comandada por la revista Vuelta de Octavio Paz, en la que participaron muchos otros reconocidos intelectuales —uno de los exhortos públicos dirigidos al presidente de la república fue suscrito por 57 científicos y literatos, entre quienes se encontraban Edmundo

6. "El Greco y las alcabalas contra el arte mexicano", en "Pro y Contra", columna de Excélsior, I de enero de I950, pp. 7 y I 2. 
O’Gorman, Emilio Rosenblueth, Fernando Benítez, Rubén Bonifaz Nuño, Emilio Carballido, Carlos Fuentes, José Luis Martínez, Eduardo Mata y Miguel León-Portilla—, se volvieron a otorgar algunas condonaciones fiscales.7 Que el movimiento de protesta pública no fue liderado por artistas visuales lo confirma el hecho de su exigua participación; sólo firmaron el documento citado Manuel Álvarez Bravo, Alfredo Zalce, Juan Soriano, Francisco Toledo, José Luis Cuevas y Manuel Felguérez.

El Programa Pago en Especie, desde su gestación, era una más de las estrategias habilitadas para acrecentar los acervos públicos de arte contemporáneo destinados a entregarse como dote a un proyectado Museo de Arte Moderno, mismo que después de más de una década de gestación logró materializarse en el Bosque de Chapultepec. Una estrategia paralela al trueque pago en especie se produjo durante la administración de Carmen Marín de Barreda al frente del Salón de la Plástica Mexicana, entre 1953 y 1955. Lo que había empezado en 1949 como una incursión del Instituto Nacional de Bellas Artes en el territorio del mercado del arte (dado que el objetivo inicial era que una galería estatal ofertara obra contemporánea destinada al consumo privado sin que al artista se le descontaran los habituales porcentajes que cualquier galería particular cobra), se convirtió en 1953 en un instrumento para rescatar piezas del mercado, patrimonializarlas y destinarlas al futuro museo mediante la fabricación de concursos abiertos con premios de adquisición.

En dicha tarea, la entonces novata promotora cultural contó con el apoyo de Marte R. Gómez, presidente del patronato del spM. No coincidieron, sin embargo, en que Gómez aspirara a crear una galería de arte nacional, acto que se consumó sólo en 1982 con el nacimiento del Museo Nacional de Arte (Munal). Así, cuando la directora del SPM le envía el borrador de los estatutos, responde:

Lo que más quisiera modificar es el programa del Patronato que detuvieron ustedes con cierta mezquindad — perdóneme la expresión—, al asignarle la misión de fundar un Museo de Arte Moderno Mexicano. Lo que México necesita es su Museo de Pintura y que en él quepan desde los códices hasta los modernos o por lo menos hasta los modernos ya aceptados por la crítica [...] ¿No quiere usted modificar su

7. Sobre el debate entre clanes de intelectuales acerca de la exención tributaria y la vigencia de los derechos patrimoniales y su transmisión, véase Zaid, op. cit., pp. 43-48, y Carlos Elizondo Mayer-Serra, "Del privilegio de crear al privilegio de no pagar impuestos", Nexos, núm. 306, I de junio de 1993 (http://www.nexos.com.mx/?P=leerarticulov2print\&Article=447252). 
circular y decir que entre nuestras aspiraciones destaca la de construir el Museo de Pintura de México? ${ }^{8}$

Por el presidencialismo que caracterizó al régimen predominante en el siglo pasado, el proyecto fue sometido a consideración del ejecutivo en turno. En 1954, Marín de Barreda - ex cuñada de Diego Rivera y esposa de un prominente miembro del grupo Contemporáneos- sostuvo una larga entrevista con el presidente Adolfo Ruiz Cortines; en sus memorias escribió:

Eran [...] [varias] las peticiones que debía hacerle. En principio [...] la explicación detallada del programa con la intención de solicitarle un edificio para el futuro Museo de Arte Moderno (мам) [...] Se interesó extraordinariamente con la idea [...] Y no acababa ahí mi gestión, representaba a los pintores Diego Rivera y Siqueiros para transmitir el mensaje al presidente relativo a su pago de impuestos. Con objeto de responsabilizarse con la Hacienda mexicana y dada su naturaleza de artistas, solicitaban que su pago de impuestos fuera consumado en especie, es decir, con su propio arte, sus cuadros. De esta manera, cumplimentaban religiosamente su condición de ciudadanos, con esta transacción satisfacían cabalmente su condición peculiar y se adecuaría a la naturaleza profunda de su oficio y, finalmente, acrecentarían el acervo estético nacional [...] Esta solicitud, también fue aceptada. ${ }^{9}$

Todo indica que, al presentar su renuncia al SPM en 1955 tanto Marín de Barreda como Gómez, el mecanismo patrimonializador, que consistía en la apropiación de las obras ganadoras de sus concursos, se interrumpió. Más aún, al materializarse el proyecto del Museo de Arte Moderno en 1964 (con Marín de Barreda como directora fundadora), el sistema de recaudación de impuestos diseñado en exclusiva para técnicas como pintura, escultura y grabado estaba suspendido y las 42 obras recaudadas en 1957 permanecían embodegadas. La única fórmula para hacer coincidir ambos proyectos fue establecer convenios entre el мам y la Secretaría de Hacienda para que, mediante préstamos

8. Carta de Marte R. Gómez a Carmen Marín de Barreda, México, 25 de septiembre de 1953, Archivo Marte R. Gómez. Estoy en deuda con Marte Gómez Leal por su generosidad al proporcionarme una selección de la correspondencia inédita de su padre.

9. "Memorias de Carmen Marín de Barreda”, I954, texto mecanografiado, pp. I68-170, I80 y I 87. Agradezco a Beatriz Sánchez de Tagle, depositaria del archivo de Carmen Marín de Barreda, por permitirme consultar este documento. 
en comodato, se garantizara la exhibición de las piezas; ${ }^{10}$ a pesar de que originalmente se había planeado, la Secretaría de Hacienda no confirió la propiedad permanente de dicho patrimonio al Instituto Nacional de Bellas Artes.

Lo cierto es que lo de 1957 sólo había sido "llamarada de petate" y que, como muchas noticias de índole político-cultural que son objeto de una campaña mediática, el programa fiscal no se formalizó hasta 1975, casi 20 años después de ser anunciado públicamente. Tengo para mí que el nombramiento de Margáin como titular de la Secretaría de Hacienda (1970-1973) fue lo que reactivó el programa, aunque por su ruptura intempestiva con el presidente Luis Echeverría Álvarez el decreto presidencial que lo legalizaba fue firmado bajo la gestión de su sucesor. ${ }^{\text {II }}$

Una vez más, el dispositivo se enfocó en atraer a artistas que contaban con un mercado ya muy establecido, entre los cuales sobresalen José Chávez Morado, Ángela Gurría, Feliciano Béjar, Rodolfo Morales y José Luis Cuevas; además, se destacó en medios la participación de pintores activos desde décadas anteriores que ya entonces gozaban de alta demanda y visibilidad en el universo del arte, como Roger von Gunten, Francisco Corzas, Roberto Doniz y Arnaldo Coen. De esta forma, cuando los pintores del movimiento rupturista ingresaron al programa a partir de su oficialización, su periodo de emergencia y vanguardia mayor había pasado; por ejemplo, no fue sino hasta la década de los años ochenta cuando se incorporaron Vicente Rojo y Manuel Felguérez — de quienes se acopian cantidades suficientes de trabajos que, en sí mismos, posibilitan la estructuración de retrospectivas - acompañados de Arnold Belkin, Francisco Corzas, Roger von Gunten y Rafael Coronel. Años después lo hicieron Mathias Goeritz, Juan Soriano, José Luis Cuevas, Francisco Toledo y Alberto Gironella, entre otros.

Cabe destacar que la bifurcación de las dos instituciones originalmente pensadas como complementarias - el mam y el Programa Pago en Especie- tuvo como consecuencia que las obras conferidas en dación de impuestos permanecieran embodegadas durante largos periodos (salvo las exposiciones temporales que

Io. Convenio firmado el 2I de diciembre de 1966 entre la Secretaría de Hacienda y la Secretaría de Educación Pública. Archivo Histórico de la Secretaría de Hacienda y Crédito Público-Dirección General de Promoción Cultural, Obra Pública y Acervo Patrimonial/Subdirección de Control de Colecciones, Recaudación, carpeta 49, I983. Se traspasaron en comodato I 5 piezas colectadas en 1957 con la estrategia paralela del sPM.

I I. Para los diversos decretos y adecuaciones del Programa, véase el interesante ensayo de Edgardo Ganado Kim, "La colección Pago en Especie, una historia por completar", en Colección Pago en Especie de la SHCP 1997-2002, México, Secretaría de Hacienda y Crédito Público, 2002, s.p. 
se realizaban con intermitencia en la Biblioteca Lerdo de Tejada y en galerías no permanentes ubicadas en Guatemala número 8 e Hidalgo número 79), hasta que en 1994, en los últimos días del gobierno de Carlos Salinas de Gortari, se inauguró el Museo de la Secretaría de Hacienda. En Moneda número 4 se concentró el acervo que se había empezado a formar, con una larga pausa, desde 1957.

Por su ubicación en uno de los dos circuitos turístico-culturales de la capital mexicana, el Museo de la Secretaría de Hacienda-Palacio del Antiguo Arzobispado tenía garantizada la afluencia de públicos. Como era usual en la modernidad, los acervos se habían constituido antes que el espacio donde se exhibirían con sistematicidad. En éste, como en innumerables casos, es notable el desfase cronológico entre la formación de colecciones y la fundación del museo que les garantice conservación adecuada, investigación y difusión. ${ }^{12}$

El hecho de que hasta 1994 la mayor parte de lo recaudado permaneció embodegado debió desalentar la incorporación de los artistas más notables de la época al Programa Pago en Especie o, en caso de solicitar su registro, por lo menos los disuadió de remitir obras paradigmáticas de su producción, aunque, por supuesto, existen honrosas excepciones. Una consecuencia de ello fue que, con escasa previsión de futuro, algunos creadores registrados en el programa seleccionaron obras de dudosa calidad que mal los representan en las exposiciones realizadas desde $1994, y$, por la inoperancia del reglamento vigente, los miembros del comité de expertos poco pueden hacer para impedirlo. ${ }^{\text {I3 }}$

Peor aún, también desalienta a los artistas una claúsula de la polémica reglamentación según la cual las obras acopiadas cada año deben repartirse por sorteo, independientemente de sus valores plásticos, en tres bloques: uno se incorpora a la colección permanente del Museo de la Secretaría de Hacienda-Palacio del Antiguo Arzobispado, otro se destina a los estados de la república y el tercero a los municipios.

I 2. Una característica del surgimiento de los museos y no sólo en México; por ejemplo, la colección privada de Álvar Carrillo Gil se formó entre 1938 y 1965 y el Museo de Arte Contemporáneo Álvar y Carmen T. de Carrillo Gil no se inauguró hasta I974. En cuanto a los movimientos plásticos, también es sistémico el desfase entre su periodo álgido de creación y su musealización; al menos esto ocurrió con la corriente artística nacida a principios de la década de los años veinte, que no logró ingresar a las salas del Museo Nacional de Artes Plásticas sino hasta la segunda mitad de los años cuarenta.

I 3. En 20 io participaban en la comisión Itala Schmelz, Susana Sierra, José Luis Cuevas, Jorge Reynoso Pohlenz, Roger von Gunten, Andrea di Castro y Eduardo Abaroa (http://www.ccpslp. org.mx/download/Boletin-Fiscal-3erBimestre.pdf). 
En la actualidad, el acervo se caracteriza por una mixtura ecléctica que hoy asciende a la impresionante cifra de alrededor de 5000 piezas, en la que coexisten ejercicios plásticos de maestros consagrados, artistas de mediana carrera y talentos jóvenes. $\mathrm{Y}$, sobre todo, predomina una desigualdad crónica en calidades y emblemáticos faltantes, tanto en personalidades creadoras y narrativas estéticas como en lenguajes y formatos, ya que en este último tema sobresalen las técnicas tradicionales. ${ }^{\mathrm{I}}$

De esta forma, los acervos del Museo de la Secretaría de Hacienda se han cimentado y se siguen construyendo de manera fortuita, sin programación ni diseño, sin un plan maestro de crecimiento que delinee una morfología ideal, al menos potencial. Convertir un acervo con crecimiento asegurado en una colección — con límites, contenidos y huecos por llenar- es una tarea ardua pero posible. Ciertamente existen serias desventajas por el predominio de leyes y reglamentos que parecen funcionar en el terreno administrativo, pero que obstaculizan la instrumentación de un proceso de selección con base en criterios estéticos; pero no sería éste el único caso de reconfiguración de un acervo heredado. ${ }^{\text {Is }}$ Es claro que en cuanto a la metodología de adquisiciones para fortalecer las colecciones del Museo de la Secretaría de Hacienda hay una reforma administrativa que urge realizar.

Y para finalizar: con la polémica pública suscitada a principios de la década de los años noventa por las modificaciones tributarias reseñadas en páginas anteriores - lo cual representó un punto de quiebre en la relación clientelar entre el Estado mexicano y los intelectuales, y que probablemente obedecía a una regulación fiscal preparatoria del Tratado de Libre Comercio (TLC) entre México, Estados Unidos y Canadá, puesto en vigor en 1994-, es factible creer que la fundación del Museo de la Secretaría de Hacienda respondió a la tentativa de fortalecer el Programa Pago en Especie con opción preferente entre la comunidad de artistas plásticos y que con ello se pretendía llevar a cabo por completo un pacto planteado hace 55 años. \$

I4. Programa Pago en Especie: 86 por ciento de pintura y gráfica, I 2 por ciento de escultura, 2 por ciento de fotografía (datos de 2006). Dirección General de Promoción Cultural, Obra Pública y Acervo Patrimonial de la Secretaría de Hacienda y Crédito Público, Informe de rendición de cuentas, gestión 200 I-2006: Libro de los Bienes del Acervo Patrimonial y de la Colección Pago en Especie, México, Patrimonio Cultural de la Nación, 2006, p. 25.

I 5. El Museo Universitario de Arte Contemporáneo de la Universidad Nacional Autónoma de México (inaugurado en 2008) inició la edificación de una colección de arte contemporáneo en la que se incluyen piezas acopiadas durante décadas por su antecesor, el Museo Universitario de Ciencias y Arte, a partir de la creación de comités académicos y artísticos. 